\title{
Lung cancer mortality in nickel/chromium platers, 1946-95
}

\author{
Tom Sorahan, Denys C L Burges, Linda Hamilton, J Malcolm Harrington
}

\begin{abstract}
Objectives-To investigate mortality from lung cancer in nickel/chromium platers. Methods-The mortality experience of a cohort of 1762 chrome workers $(812 \mathrm{men}$, 950 women) from a large electroplating and light engineering plant in the Midlands, United Kingdom, was investigated for the period 1946-95. All subjects were first employed in chrome work at the plant during the period 1946-75, and had at least six months employment in jobs associated with exposure to chromic acid mist (hexavalent chromium). Detailed job histories were abstracted from original company personnel records and individual cumulative durations of employment in three types of chrome work were derived as time dependent variables (chrome bath work, other chrome work, any chrome work). Two analytical approaches were usedindirect standardisation and Poisson regression.
\end{abstract}

Results-Based on mortalities for the general population of England and Wales, male workers with some period of chrome bath work had higher lung cancer mortalities (observed deaths 40, expected deaths 25.41, standardised mortality ratio (SMR) $157,95 \%$ confidence interval $(95 \%$ CI) 113 to $214, p<0.01$ ) than did other male chrome workers (observed 9, expected 13.70, SMR 66, 95\% CI 30 to 125). Similar findings were shown for female workers (chrome bath workers: observed 15, expected 8.57 , SMR $175,95 \%$ CI 98 to 289 , p=0.06; other chrome workers: observed 1, expected 4.37, SMR 23, 95\% CI 1 to 127). Poisson regression was used to investigate risks of lung cancer relative to four categories of cumulative duration of chrome bath work and four categories of cumulative duration of other chrome work (none, <1 y, 1-4 y, $\geqslant 5$ y). After adjusting for sex, age, calendar period, year of starting chrome work, period from first chrome work, and employment status (still employed $v$ left employment), there was a significant positive trend $(p<0.05)$ between duration of chrome bath work and risks of mortality for lung cancer. Relative to a risk of unity for those chrome workers without any period of chrome bath work, risks were 2.83 (95\% CI 1.47 to $5.45), 1.61$ (95\% CI 0.75 to 3.44$)$, and 4.25 (95\% CI 1.83 to 9.87$)$ for the second, third, and fourth exposure categories, respectively. Duration of other chrome work was not a useful predictor of risks of lung can- cer. Similar findings for both variables were obtained when adjustment was made for sex and age only. Similar findings for both variables were obtained relative to risk of chrome nasal ulceration.

Conclusions-The findings are consistent with the hypothesis that soluble hexavalent chromium compounds are potent human lung carcinogens.

(Occup Environ Med 1998;55:236-242)

Keywords: chrome plating; lung cancer; cohort study

It has been recognised for many years that contact with chromic acid can cause a chronic type of ulceration which is slow to heal and leads to permanent scarring. For example, in 1967, Her Majesty's Factory Inspectorate stated that, with reference to chromic acid mist, "ulcers... on the fingers or hands... are usually the outcome of lack of personal measures of protection... Nasal ulceration is, in contrast, usually due to airborne mist (or) spray... and most commonly denotes a failure of plant control." "At that time, there was "no... evidence of an association (between cancer of the lung) and the use of hexavalent chromium compounds". In the intervening years several epidemiological and experimental studies have been carried out, and the most recent evaluation by a Working Group of the International Agency for Research on Cancer (IARC) on the carcinogenicity of chromium and chromium compounds concluded that there was sufficient evidence in humans for the carcinogenicity of chromium[VI] compounds as encountered in the chromate production, chromate pigment production, and chromium plating industries. ${ }^{2}$ Also, there was judged to be sufficient evidence in experimental animals for the carcinogenicity of calcium chromate, zinc chromates, strontium chromate, and lead chromates. The overall evaluation was that chromium[VI] (hexavalent chromium) is carcinogenic to humans (group I carcinogen). Eight reports relating to five cohort studies of chrome platers were available for this evaluation. ${ }^{3-10}$ In the largest of these studies, a striking difference in standardised mortality ratios (SMRs) for lung cancer was found among men first employed as chrome bath workers (SMR 199, observed 46) and men first employed as other chrome workers (SMR 100, observed 17); chrome bath workers were the more heavily exposed. ${ }^{10}$ Findings from two later reports of Japanese chromium platers ${ }^{11}{ }^{12}$ have not disturbed the general consensus that chrome plating has caused occupational lung cancers. Risks have 
Table 1 Chrome platers'study, distribution of deaths and person-years at risk, 1946-95

\begin{tabular}{|c|c|c|c|}
\hline Variable with levels & Lung cancers* & All other causest & Person-years at risk \\
\hline \multicolumn{4}{|c|}{ Cumulative duration of chrome bath work $\ddagger(y)$ : } \\
\hline None & 13 & 213 & 15038.6 \\
\hline$<1$ & 32 & 208 & 16780.2 \\
\hline $1-4$ & 14 & 143 & 13311.6 \\
\hline$\geqslant 5$ & 10 & 57 & 3004.7 \\
\hline \multicolumn{4}{|c|}{ Cumulative duration of other chrome work $₫(y)$ : } \\
\hline None & 43 & 337 & 28450.7 \\
\hline$<1$ & 9 & 137 & 9672.8 \\
\hline $1-4$ & 13 & 115 & 8218.4 \\
\hline$\geqslant 5$ & 4 & 32 & 1793.2 \\
\hline \multicolumn{4}{|l|}{ Sex: } \\
\hline Male & 52 & 369 & 20844.6 \\
\hline Female & 17 & 252 & 27290.5 \\
\hline \multicolumn{4}{|l|}{ Calendar period: } \\
\hline $1946-55$ & 2 & 23 & 3611.7 \\
\hline $1956-65$ & 10 & 84 & 10166.9 \\
\hline $1966-75$ & 20 & 156 & 13104.7 \\
\hline $1976-85$ & 18 & 188 & 12069.3 \\
\hline $1986-95$ & 19 & 170 & 9182.5 \\
\hline \multicolumn{4}{|l|}{ Attained age: } \\
\hline $30-39$ & 2 & 17 & 8865.4 \\
\hline $40-49$ & 3 & 50 & 12290.3 \\
\hline $50-54$ & 5 & 32 & 6478.7 \\
\hline $55-59$ & 11 & 72 & 6132.5 \\
\hline $60-64$ & 12 & 93 & 5302.8 \\
\hline $65-69$ & 15 & 113 & 4113.9 \\
\hline $70-74$ & 11 & 90 & 2708.6 \\
\hline $75-79$ & 7 & 95 & 1521.8 \\
\hline $80-84$ & 3 & 59 & 721.1 \\
\hline \multicolumn{4}{|c|}{ Period from first chrome work (y): } \\
\hline $0-9$ & 5 & 74 & 11878.9 \\
\hline $10-19$ & 23 & 141 & 14687.6 \\
\hline$\geqslant 20$ & 41 & 406 & 21568.6 \\
\hline \multicolumn{4}{|l|}{ Employment status : } \\
\hline Still employed & 4 & 27 & 4583.0 \\
\hline Left employment & 65 & 594 & 43552.1 \\
\hline \multicolumn{4}{|c|}{ Year of starting chrome work (chrome bath or other): } \\
\hline $1946-50$ & 25 & 285 & 18650.8 \\
\hline $1951-55$ & 27 & 201 & 12492.5 \\
\hline $1956-60$ & 11 & 81 & 7894.9 \\
\hline $1961-75$ & 6 & 54 & 9096.9 \\
\hline Total & 69 & 621 & 48135.1 \\
\hline
\end{tabular}

*Any part of death certificate coded to ICD-8 162-163.

†No part of death certificate coded to ICD-8 162-163.

¥Chrome bath workers (chrome platers, nickel/chrome platers, jiggers and unjiggers).

SViewers, degreasers, material handlers, jig maintenance, strippers, passivators (zinc platers).

"Subjects are entered into the person-years at risk for the "left employment" group three

months after leaving employment.

yet to be measured and data from the largest available study ${ }^{10}$ have been revisited to start this exercise.

\section{Materials and methods}

MATERIALS

Chrome plating carried out at the factory was of the decorative type and factory processes and conditions have been described previously ${ }^{10}$; a general account of the manufacturing processes involved in electroplating is available. ${ }^{13}$ The population available for study comprised 3085 workers (1682 men, 1403 women) who started chrome work either as a chrome bath worker (plater, jigger, unjigger) or in other jobs carried out in the workshops containing the chrome baths (degreaser, viewer, general labourer, jig maintenance worker, stripper, passivator) in a large electroplating and metal engineering plant in the Midlands (United Kingdom) between 1946 and 1975. This cohort has been described previously ${ }^{10}$; all subjects were employed for at least six months in chrome jobs. A total of 396 employees with Asian surnames were excluded from the previous report ${ }^{10}$ because overall mortality had been suspiciously low for this group; the updated SMR for all causes is 43 (expected=93.5, observed $=40, \mathrm{p}<0.001)$. This finding probably represents inadequate tracing for these workers and they were not included in the initial revised study population of 2689 employees.

At the outset of this analysis, computerised job histories available for all members of the study cohort were limited to the first period of chrome work (type of work, years of starting and leaving chrome work). An attempt has been made, therefore, to improve the usefulness of the revised analysis by improving the quality of the computerised job history data. The factory closed down in 1980 but the original personnel records had been maintained by one of us (DCLB). For each study subject, details for all periods of employment at the factory (department, job, and relevant dates) were abstracted from the original records in text form. After editing some of the descriptions, a job dictionary was produced with some 2450 unique department and job entries. These entries were then assessed as to whether they described chrome work, and if so, what type of chrome work (two categories of chrome bath work, six categories of other chrome work). ${ }^{10}$ This was not straightforward because many department codes had been in use at the factory and codes had changed over time. However, knowledge of the various processes allowed more appropriate designations to be 
Table 2 SMRs for lung cancer and all causes excluding lung cancer, 1946-95

\begin{tabular}{|c|c|c|c|c|c|c|c|c|c|c|c|c|c|c|c|c|}
\hline & \multicolumn{8}{|c|}{ Lung cancer } & \multicolumn{8}{|c|}{ All other causes } \\
\hline & \multicolumn{4}{|c|}{ Men } & \multicolumn{4}{|c|}{ Women } & \multicolumn{4}{|l|}{ Men } & \multicolumn{4}{|c|}{ Women } \\
\hline & $O b s$ & $\operatorname{Exp}$ & $S M R$ & $(95 \% C I)$ & $O b s$ & $\operatorname{Exp}$ & $S M R$ & $(95 \% C I)$ & $O b s$ & $\operatorname{Exp}$ & $S M R$ & $(95 \% C I)$ & $O b s$ & $\operatorname{Exp}$ & $S M R$ & $(95 \% C I)$ \\
\hline \multicolumn{17}{|c|}{ Period from first chrome work (y): } \\
\hline $0-9$ & 5 & 4.87 & 103 & (33 to 240 ) & 0 & 0.68 & 0 & ( 0 to 542$)$ & 57 & 46.86 & 122 & (92 to 157 ) & 21 & 24.48 & 86 & (53 to $(131)$ \\
\hline $10-19$ & 18 & 8.85 & $203^{\star \star}$ & (121 to 321$)$ & 3 & 1.99 & 151 & (31 to 441 ) & 93 & 77.24 & 120 & (97 to 148 ) & 51 & 49.18 & 104 & (77 to 136 ) \\
\hline $20-29$ & 16 & 11.15 & 143 & (82 to 233 ) & 3 & 4.07 & 74 & (15 to 215 ) & 105 & 92.75 & 113 & (93 to 137 ) & 74 & 78.88 & 94 & (74 to 118 ) \\
\hline$\geqslant 30$ & 10 & 14.24 & 70 & (34 to 129 ) & 10 & 6.19 & 162 & (78 to 297 ) & 119 & 121.87 & 98 & (81 to 117 ) & 110 & 113.51 & 97 & (80 to 117 ) \\
\hline \multicolumn{17}{|c|}{ Year of starting chrome work: } \\
\hline $1946-50$ & 17 & 20.07 & 85 & (49 to 136 ) & 6 & 4.95 & 121 & (44 to 265 ) & 174 & 178.74 & 97 & (83 to 113 ) & 114 & 120.79 & 94 & (78 to 113$)$ \\
\hline $1951-55$ & 22 & 10.49 & $210^{\star \star}$ & (132 to 317$)$ & 5 & 3.55 & 141 & (46 to 330 ) & 125 & 89.58 & $140^{\star \star \star}$ & (116 to 166$)$ & 76 & 75.03 & 101 & (80 to 127 ) \\
\hline $1956-60$ & 7 & 4.90 & 143 & (57 to 294 ) & 3 & 2.17 & 138 & (29 to 404$)$ & 47 & 40.24 & 117 & (86 to 155$)$ & 36 & 36.36 & 99 & (70 to 137 ) \\
\hline $1961-75$ & 3 & 3.65 & 82 & (17 to 240 ) & 2 & 2.28 & 88 & (11 to 317 ) & 28 & 30.15 & 93 & (62 to 134 ) & 30 & 33.87 & 89 & (60 to 126$)$ \\
\hline \multicolumn{17}{|c|}{ Cumulative duration of chrome bath work $\ddagger(y)$ : } \\
\hline None & 9 & 13.70 & 66 & ( 30 to 125 ) & 1 & 4.37 & 23 & (1 to 127$)$ & 128 & 125.99 & 102 & ( 85 to 121$)$ & 89 & 90.60 & 98 & (79 to 121 ) \\
\hline$<1$ & 22 & 12.77 & $172^{\star}$ & (108 to 261$)$ & 10 & 4.08 & $245^{\star}$ & (118 to 451$)$ & 135 & 109.34 & $123^{\star}$ & (103 to 146$)$ & 75 & 85.19 & 88 & (69 to 110$)$ \\
\hline $1-4$ & 8 & 9.97 & 80 & (35 to 159 ) & 5 & 3.55 & 141 & (46 to 330 ) & 84 & 83.08 & 101 & (81 to 125$)$ & 62 & 67.47 & 92 & (70 to 118 ) \\
\hline$\geqslant 5$ & 10 & 2.67 & $375^{\star \star \star}$ & (180 to 689 ) & 0 & 0.94 & 0 & (0 to 392$)$ & 27 & 20.30 & 133 & (88 to 194 ) & 30 & 22.79 & 132 & (89 to 188 ) \\
\hline $\mathrm{p}$ Value for & trend & $(0.009$ & & & & $(0.477)$ & & & & $(0.484)$ & & & & $(0.460)$ & & \\
\hline \multicolumn{17}{|c|}{ Cumulative duration of chrome bath work (y), employment histories lagged by $10 \mathrm{y}$ : } \\
\hline None & 13 & 16.29 & 80 & (42 to 136 ) & 1 & 4.83 & 21 & ( 1 to 115 ) & 161 & 150.73 & 107 & (91 to 125 ) & 100 & 107.24 & 93 & (76 to 114 ) \\
\hline$<1$ & 21 & 11.60 & $181^{\star}$ & (112 to 277$)$ & 10 & 3.91 & $256^{\star}$ & (123 to 471$)$ & 121 & 97.02 & $125^{\star}$ & (103 to 149$)$ & 70 & 78.49 & 89 & (70 to 113 ) \\
\hline $1-4$ & 8 & 9.03 & 89 & (38 to 175 ) & 5 & 3.36 & 149 & (48 to 348$)$ & 72 & 74.41 & 97 & (76 to 122$)$ & 60 & 60.73 & 99 & (75 to 127 ) \\
\hline$\geqslant 5$ & 7 & 2.19 & $320^{\star}$ & (128 to 658 ) & 0 & 0.85 & 0 & (0 to 434$)$ & 20 & 16.55 & 121 & (74 to 187 ) & 26 & 19.59 & 133 & (87 to 194 ) \\
\hline $\mathrm{p}$ Value for & trend & $(0.053$ & & & & $(0.326)$ & & & & $(0.944)$ & & & & $(0.335)$ & & \\
\hline \multicolumn{17}{|c|}{ Cumulative duration of any chrome work $\neq \(y)$ : } \\
\hline$<1$ & 22 & 17.66 & 125 & (78 to 189 ) & 8 & 5.41 & 148 & (64 to 292 ) & 180 & 153.83 & $117^{\star}$ & (101 to 135$)$ & 103 & 113.66 & 91 & (74 to 110 ) \\
\hline $1-$ & 11 & 9.81 & 112 & (56 to 201 ) & 3 & 2.91 & 103 & (21 to 301$)$ & 85 & 84.35 & 101 & (80 to 124$)$ & 52 & 55.07 & 94 & (70 to 124 ) \\
\hline $2-4$ & 3 & 6.35 & 47 & (10 to 138 ) & 5 & 3.11 & 161 & (52 to 376 ) & 64 & 56.45 & 113 & (87 to 145$)$ & 53 & 62.86 & 84 & (63 to 110 ) \\
\hline$\geqslant 5$ & 13 & 5.28 & $246^{\star \star}$ & (131 to 420$)$ & 0 & 1.51 & 0 & (0 to 244 ) & 45 & 44.09 & 102 & (74 to 137 ) & 48 & 34.46 & $139^{\star}$ & (103 to 185 ) \\
\hline $\mathrm{p}$ Value for & trend & $(0.291$ & & & & $(0.358)$ & & & & $(0.443)$ & & & & $(0.160)$ & & \\
\hline \multicolumn{17}{|c|}{ Cumulative duration of any chrome work (y), employment histories lagged by $10 \mathrm{y}$ : } \\
\hline$<1$ & 27 & 20.85 & 129 & (85 to 188$)$ & 9 & 5.87 & 153 & (70 to 291 ) & 216 & 183.92 & $117^{\star}$ & (102 to 134$)$ & 117 & 129.24 & 91 & (75 to 108$)$ \\
\hline $1-$ & 8 & 8.46 & 95 & (41 to 187 ) & 3 & 2.79 & 108 & (22 to 314 ) & 71 & 71.62 & 99 & $(77$ to 125$)$ & 47 & 50.60 & 93 & (68 to 124$)$ \\
\hline $2-4$ & 5 & 5.62 & 89 & (29 to 208 ) & 4 & 2.93 & 137 & (37 to 348 ) & 52 & 48.56 & 107 & (80 to 140 ) & 51 & 56.75 & 90 & (67 to 118 ) \\
\hline \multirow{2}{*}{\multicolumn{2}{|c|}{$\mathrm{p}$ Value for trend }} & 4.13 & 218 & $(100$ to 414$)$ & 0 & 1.36 & 0 & (0 to 271$)$ & 35 & 34.61 & 101 & (70 to 141 ) & 41 & 29.45 & 139 & (100 to 189$)$ \\
\hline & & $(0.512$ & & & & $(0.260)$ & & & & $(0.292)$ & & & & $(0.144)$ & & \\
\hline Total & 49 & 39.11 & 125 & (93 to 166 ) & 16 & 12.94 & 124 & (71 to 201 ) & 374 & 338.71 & 110 & (99 to 122 ) & 256 & 256.05 & 96 & (85 to 109 ) \\
\hline
\end{tabular}

${ }^{\star} \mathrm{p}<0.05 ;{ }^{\star \star} \mathrm{p}<0.01 ;{ }^{\star \star \star} \mathrm{p}<0.001$

Other footnotes as for table 1 .

made. For example, if a department included many job entries for assembly, then a degreaser in this department could not be exposed to chrome because assembly work did not take place in any of the chrome bath workshops. The final chrome work codes associated with each entry in the job dictionary were then cross referenced with individual job history details in the study computer file.

Personnel records could not be found for 660 employees, 31 employees had started chrome work before 1946, and a further 236 employees were judged to have no period of chrome work. (In the previous report, most employees in the group with no period of chrome work had been coded as inspectors or degreasers $(n=118)$.) All of these three groups were excluded from the final revised study population which comprised 1762 employees (812 men, 950 women). Most (61\%) of the employees with missing personnel records had surnames beginning with the letters A-G; the corresponding percentage for the final revised study population was only $31 \%$. It was known by one of us (DCLB) that a box of personnel records had gone missing in the early years of the study (1970s).

The newly abstracted job history data should be seen as a refinement of the earlier data. ${ }^{10}$ For example, of the 1762 employees in the final revised study population, there are now 1201 employees with some period of chrome bath work (mean duration of chrome bath work $=1.91$ years, mean duration of other chrome work $=0.23$ years), whereas 1185 of the 1762 employees had been coded as chrome bath workers in the earlier report ${ }^{10}$ (mean duration of any type of chrome work $=2.58$ years).

The Office for National Statistics (ONS) provided information on the vital status of each person on the closing date of the survey: 827 subjects were traced alive, 69 subjects had emigrated, 752 subjects were dead, and 114 subjects were untraced. From information supplied by the Department of Social Security, 58 of the untraced subjects were known to be alive at the end of 1983. For those subjects known to have died, a death certificate was obtained with the underlying cause of death coded to the 8th revision of the international classification of diseases (ICD-8). Mortality was investigated for the period 1 January 1946 to 31 December 1995.

METHODS

External standard: SMR approach

The mortality experience of the cohort was compared with that which might have been expected to occur if mortalities for the general population of England and Wales had been operating on the study cohort, with due regard to the composition of the study cohort by age, sex, and calendar year.

Expectations based on person-years at risk were calculated with the EPICURE ${ }^{14}$ computer 
Table 3 Relative risks of mortality from lung cancer and other causes by levels of cumulative duration of chrome work (six separate analyses) obtained from a multiplicative model and analysed simultaneously with sex and attained aget

\begin{tabular}{|c|c|c|c|c|c|c|}
\hline \multirow[b]{2}{*}{ Variable with levels } & \multicolumn{3}{|c|}{ Lung cancer $\neq$} & \multicolumn{3}{|c|}{ All other causes $\int$} \\
\hline & $n$ & $R R$ & $(95 \% C I)$ & $n$ & $R R$ & $(95 \% C I)$ \\
\hline \multicolumn{7}{|c|}{ Model 1: Cumulative duration of chrome bath work $\mathbf{f}(\mathrm{y})$ : } \\
\hline None & 13 & 1.0 & & 213 & 1.0 & \\
\hline$<1$ & 32 & $2.64^{\star \star}$ & $(1.38$ to 5.03$)$ & 208 & 1.06 & (0.87 to 1.28$)$ \\
\hline $1-4$ & 14 & 1.46 & $(0.68$ to 3.10$)$ & 143 & 0.92 & $(0.75$ to 1.14$)$ \\
\hline$\geqslant 5$ & 10 & $3.83^{\star \star}$ & $(1.68$ to 8.74$)$ & 57 & 1.33 & (0.99 to 1.78$)$ \\
\hline Evaluation of trend $+\dagger$ & \multirow{2}{*}{\multicolumn{3}{|c|}{ (1.03 to 1.68$)$}} & & 1.03 & $(0.95$ to 1.12$)$ \\
\hline 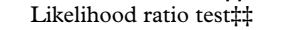 & & & & \multicolumn{2}{|c|}{$\mathrm{p}=0.14$} & \\
\hline \multicolumn{7}{|c|}{ Model 2: Cumulative duration of other chrome work $\$ \int(y)$ : } \\
\hline None & 43 & 1.0 & & 337 & 1.0 & \\
\hline$<1$ & 9 & 0.50 & $(0.24$ to 1.02$)$ & 137 & 1.02 & $(0.84$ to 1.25$)$ \\
\hline $1-4$ & 13 & 0.85 & (0.46 to 1.59$)$ & 115 & 0.94 & (0.76 to 1.16$)$ \\
\hline$\geqslant 5$ & 4 & 0.91 & $(0.33$ to 2.55$)$ & 32 & 0.96 & (0.67 to 1.38$)$ \\
\hline Evaluation of trend $+\dagger$ & & 0.91 & (0.70 to 1.18$)$ & & 0.98 & (0.90 to 1.07$)$ \\
\hline Likelihood ratio test & \multicolumn{3}{|c|}{$\mathrm{p}=0.24$} & \multicolumn{2}{|c|}{$\mathrm{p}=0.90$} & \\
\hline \multicolumn{7}{|c|}{ 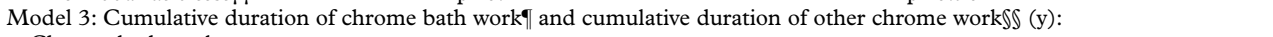 } \\
\hline \multicolumn{7}{|l|}{ Chrome bath work: } \\
\hline None & 13 & 1.0 & & 213 & 1.0 & \\
\hline$<1$ & 32 & $3.32 \star \star$ & $(1.48$ to 7.42$)$ & 208 & 1.04 & $(0.78$ to 1.38$)$ \\
\hline $1-4$ & 14 & 1.86 & (0.74 to 4.65$)$ & 143 & 0.90 & (0.66 to 1.23$)$ \\
\hline$\geqslant 5$ & 10 & $4.83^{\star \star \star}$ & (1.89 to 12.35$)$ & 57 & 1.31 & (0.92 to 1.86$)$ \\
\hline Evaluation of trend $+\dagger$ & & $1.37^{\star}$ & $(1.04$ to 1.81$)$ & & 1.02 & $(0.92$ to 1.14$)$ \\
\hline \multicolumn{7}{|l|}{ Other chrome work: } \\
\hline None & 43 & 1.0 & & 337 & 1.0 & \\
\hline$<1$ & 9 & 0.87 & $(0.39$ to 1.94$)$ & 137 & 1.02 & $(0.77$ to 1.35$)$ \\
\hline $1-4$ & 13 & 1.68 & (0.79 to 3.56$)$ & 115 & 0.94 & (0.70 to 1.27$)$ \\
\hline$\geqslant 5$ & 4 & 1.79 & (0.59 to 5.44$)$ & 32 & 0.96 & (0.63 to 1.46$)$ \\
\hline Evaluation of trend $+\dagger$ & \multirow{2}{*}{\multicolumn{3}{|c|}{ (0.81 to 1.46$)$}} & & 0.99 & (0.89 to 1.10$)$ \\
\hline Likelihood ratio test护 & & & & \multicolumn{2}{|c|}{$\mathrm{p}=0.43$} & \\
\hline
\end{tabular}

${ }^{\star} \mathrm{p}<0.05,{ }^{\star \star} \mathrm{p}<0.01,{ }^{\star \star \star} \mathrm{p}<0.001$.

†For levels, see table 1 .

$\neq$ See footnote ${ }^{\star}$, table 1 .

§See footnote $\dagger$, table 1 .

qSee footnote $\neq$, table 1 .

††Relative risk for a change in exposure of one level, calculated from coding the four cumulative duration levels $1,2,3$, and 4 and treating the variable as continuous.

$\neq \ddagger$ See text.

§SSee footnote $\S$, table 1 .

program. People entered the person-years at risk at the end of the first six months of chrome work and left on the date of death, date of embarkation (emigration), date last known alive, or the closing date of the study, whichever was the earlier. People were censored on reaching their 85th birthday - that is, they make no further contributions to expected or observed numbers past this age. The rationale for this procedure has been supplied previously. ${ }^{15}$ The SMRs were also calculated for categories of duration of chrome work. For such time dependent variables, subjects contributed person-years at risk to contemporaneous categories.

The SMRs were calculated as the ratio of observed to expected numbers of deaths expressed as a percentage. Where significance tests have been carried out, two tailed tests were used. Tests for trend were those described by Breslow and Day. ${ }^{16}$

Internal standard: Poisson regression

For the internal analyses, cases of lung cancer were selected as those deaths for which any part of the death certificate (1a, 1b, 1c, or II) would be so coded (ICD-8 162, 163). This approach introduced a further four cases of lung cancer not available to the SMR analyses. Occupational exposure to chrome was not expected to have a discernible influence on many causes of death. Consequently, mortality from all causes excluding lung cancer (as defined above) was also studied to assess the usefulness of the explanatory variables used in the statistical models. The risk of chrome ulceration was also studied.

Several variables were considered to have the potential for influencing mortality within the cohort: attained age, year of starting chrome work, sex, calendar period, period from first chrome work, employment status (still employed or left employment), cumulative duration of chrome bath work, and cumulative duration of other chrome work. These variables were not treated as continuous variables, but rather each variable was categorised into several levels. In constructing the models, it was necessary to ensure that there was at least one death observed at each level of each variable. Any adjustments were made before any statistical modelling was carried out; table 1 shows the final categories. Most of these variables are time dependent and the analysis allows subjects to contribute person-years at risk to contemporaneous categories. There were no deaths from lung cancer before the age of 30 years; analyses of both causes of death were limited, therefore, to the age range 30-84 years.

The EPICURE computer program was used to provide person-years at risk and numbers of deaths for all combinations of all levels of the selected variables. The EPICURE program was also used to carry out statistical modelling by means of Poisson regression. ${ }^{16}$ The purpose of the modelling was to establish whether the mortality experienced by the study cohort could be described easily in terms of variables such as attained age and sex, or whether the 
Table 4 Relative risks of mortality from lung cancer and other causes by levels of cumulative duration of chrome work (six separate analyses) obtained from a multiplicative model and analysed simultaneously with sex, attained age, calendar period, period from first chrome work, employment status, and year of starting chrome workt

\begin{tabular}{|c|c|c|c|c|c|c|}
\hline \multirow[b]{2}{*}{ Variable with levels } & \multicolumn{3}{|c|}{ Lung cancer $\neq$} & \multicolumn{3}{|c|}{ All other causes $\int$} \\
\hline & $n$ & $R R$ & $(95 \% C I)$ & $n$ & $R R$ & $(95 \% C I)$ \\
\hline \multicolumn{7}{|c|}{ Model 1: Cumulative duration of chrome bath work $(\mathrm{y})$ : } \\
\hline None & 13 & 1.0 & & 213 & 1.0 & \\
\hline$<1$ & 32 & $2.83^{\star \star}$ & $(1.47$ to 5.45$)$ & 208 & 1.07 & $(0.88$ to 1.30$)$ \\
\hline $1-4$ & 14 & 1.61 & $(0.75$ to 3.44$)$ & 143 & 0.97 & $(0.78$ to 1.20$)$ \\
\hline$\geqslant 5$ & 10 & $4.25^{\star \star \star}$ & (1.83 to 9.87$)$ & 57 & $1.38^{\star}$ & $(1.03$ to 1.86$)$ \\
\hline Evaluation of trend $+\dagger$ & & $1.36^{\star}$ & $(1.07$ to 1.74$)$ & & 1.05 & (0.96 to 1.14$)$ \\
\hline Likelihood ratio test㧊 & \multicolumn{3}{|c|}{$\mathrm{p}=0.001$} & \multicolumn{3}{|c|}{$\mathrm{p}=0.15$} \\
\hline \multicolumn{7}{|c|}{ Model 2: Cumulative duration of other chrome work $\$ \Phi(y)$ : } \\
\hline None & 43 & 1.0 & & 337 & 1.0 & \\
\hline$<1$ & 9 & 0.50 & $(0.24$ to 1.02$)$ & 137 & 1.01 & $(0.83$ to 1.24$)$ \\
\hline $1-4$ & 13 & 0.79 & $(0.42$ to 1.50$)$ & 115 & 0.90 & (0.72 to 1.11$)$ \\
\hline$\geqslant 5$ & 4 & 0.76 & $(0.27$ to 2.15$)$ & 32 & 0.90 & (0.62 to 1.30$)$ \\
\hline Evaluation of trend $+\dagger$ & & 0.87 & $(0.66$ to 1.13$)$ & & 0.96 & $(0.88$ to 1.04$)$ \\
\hline Likelihood ratio test㧊 & \multicolumn{3}{|r|}{ (0.66 to 1.13$)$} & \multicolumn{3}{|c|}{$\mathrm{p}=0.70$} \\
\hline \multicolumn{7}{|c|}{ Model 3: Cumulative duration of chrome bath work $\|$ and cumulative duration of other chrome work $\$ \Phi(y)$ : } \\
\hline \multicolumn{7}{|l|}{ Chrome bath work: } \\
\hline None & 13 & 1.0 & & 213 & 1.0 & \\
\hline$<1$ & 32 & $3.47^{\star \star}$ & (1.53 to 7.85$)$ & 208 & 1.04 & ( 0.78 to 1.38$)$ \\
\hline $1-4$ & 14 & 2.00 & $(0.79$ to 5.08$)$ & 143 & 0.93 & $(0.68$ to 1.27$)$ \\
\hline$\geqslant 5$ & 10 & $5.22^{\star \star \star}$ & (2.00 to 13.64$)$ & 57 & 1.33 & (0.93 to 1.91$)$ \\
\hline Evaluation of trend $+\dagger$ & & $1.40^{\star}$ & $(1.05$ to 1.86$)$ & & 1.03 & $(0.93$ to 1.15$)$ \\
\hline \multicolumn{7}{|l|}{ Other chrome work: } \\
\hline None & 43 & 1.0 & & 337 & 1.0 & \\
\hline$<1$ & 9 & 0.91 & (0.40 to 2.03$)$ & 137 & 1.02 & (0.77 to 1.36$)$ \\
\hline $1-4$ & 13 & 1.56 & (0.74 to 3.29$)$ & 115 & 0.91 & (0.67 to 1.23$)$ \\
\hline$\geqslant 5$ & 4 & 1.69 & $(0.53$ to 5.36$)$ & 32 & 0.91 & $(0.60$ to 1.40$)$ \\
\hline Evaluation of trend+† & \multirow{2}{*}{\multicolumn{3}{|c|}{ (0.78 to 1.42$)$}} & \multirow{2}{*}{\multicolumn{2}{|c|}{$\mathrm{p}=0.38$}} & (0.88 to 1.08$)$ \\
\hline 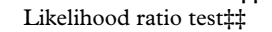 & & & & & & \\
\hline
\end{tabular}

Footnotes as for table 3 .

inclusion of any of the employment history variables made a significant contribution to the ability of the overall model to describe the data. The significance of this contribution was assessed by the likelihood ratio test (LRT) comparing deviance and degrees of freedom with and without inclusion of the variables under test. Also, the significance of any trend in risk across the four exposure categories was assessed by repeating the analysis while treating cumulative duration of chrome work as a continuous variable coded $1,2,3$, or 4 for the four levels of exposure.

\section{Results}

EXTERNAL STANDARD

Table 2 shows observed and expected numbers of deaths from lung cancer by period from first chrome work, by year of starting chrome work, by cumulative duration of chrome bath work, and by cumulative duration of any type of chrome work (chrome bath or other chrome work). A considerably increased SMR was found for all male chrome workers 10-19 years after first chrome work (observed 18, expected 8.85, SMR 203, 95\% CI 121 to $321, \mathrm{p}<0.01$ ) whereas the SMR for later periods of follow up $(\geqslant 20$ years after first chrome work) is unexceptional (observed 26, expected 25.39, SMR 102, $95 \%$ CI 67 to 150 ). A considerably increased SMR was found for those men starting chrome work in the period 1951-5 (observed 22, expected 10.49 , SMR $210,95 \%$ CI 132 to 317 , $\mathrm{p}<0.01)$. A similar excess is not found for men who started chrome work in the earlier period 1946-50 (observed 17, expected 20.07, SMR $85,95 \%$ CI 49 to 136). Male workers with some period of chrome bath work have a much higher SMR (observed 40, expected 25.41, SMR 157, 95\% CI 113 to $214, \mathrm{p}<0.01$ ) than do other male chrome workers (observed 9, expected 13.70, SMR 66, 95\% CI 30 to 125). A significant positive trend was shown for lung cancer mortality in men and cumulative duration of chrome bath work $(p<0.01)$ and a considerably increased SMR was found for men employed for five years or more as a chrome bath worker (observed 10, expected 2.67, SMR $375,95 \%$ CI 180 to $689, \mathrm{p}<0.001)$. A non-significant positive trend was found for lung cancer mortality in men and duration of any chrome work $(p=0.29)$. Female workers with some period of chrome bath work also have a much higher SMR (observed 15, expected 8.57 , SMR $175,95 \%$ CI 98 to 289 , $\mathrm{p}=0.06)$ than do other female chrome workers (observed 1, expected 4.37, SMR 23, 95\% CI 1 to 127). For women, none of the corresponding tests for trend was significant.

Table 2 also shows corresponding findings for all causes excluding lung cancer. In general, SMRs are much closer to expectation and significant positive trends were not found for SMRs and any of the duration of chrome work variables.

\section{INTERNAL STANDARD}

Table 3 provides relative risks of mortality from lung cancer and other causes by categories of cumulative duration of chrome bath work and cumulative duration of other chrome work, with simultaneous adjustment for sex and age. The first two models consider these two chrome work variables separately. The third model considers these two variables simultaneously, so that the independent effects of either variable can be assessed. The table also summarises a further six separate analyses in which the significance of any trends in risk across the four exposure categories were 
Table 5 Relative risks for diagnosis of chrome nasal ulcert and for diagnosis of nasal problems $\ddagger$ by levels of cumulative duration of chrome work (two separate analyses) obtained from a multiplicative model and analysed simultaneously with sex and attained age

\begin{tabular}{|c|c|c|c|c|c|c|}
\hline \multirow[b]{2}{*}{ Variable with levels } & \multicolumn{3}{|c|}{ Chrome nasal ulcert } & \multicolumn{3}{|c|}{ Nasal problems $\neq$} \\
\hline & $n$ & $R R$ & $95 \% C I$ & $n$ & $R R$ & $95 \% C I$ \\
\hline \multicolumn{7}{|c|}{ 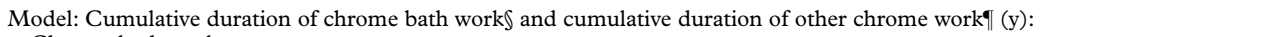 } \\
\hline \multicolumn{7}{|l|}{ Chrome bath work: } \\
\hline None & 2 & 1.0 & & 14 & 1.0 & \\
\hline$<1$ & 4 & 2.08 & (0.29 to 14.88$)$ & 33 & 1.69 & $(0.67$ to 4.25$)$ \\
\hline $1-4$ & 5 & 4.65 & $(0.69$ to 31.35$)$ & 18 & 1.58 & (0.60 to 4.17$)$ \\
\hline$\geqslant 5$ & 5 & $15.88^{\star \star}$ & (2.38 to 105.9$)$ & 14 & $4.38^{\star \star}$ & (1.63 to 11.75$)$ \\
\hline Evaluation of trend $+\dagger$ & & $2.67^{\star \star \star}$ & $(1.49$ to 4.75$)$ & & $1.47^{\star \star}$ & (1.11 to 1.95$)$ \\
\hline \multicolumn{7}{|l|}{ Other chrome work: } \\
\hline None & 10 & 1.0 & & 57 & 1.0 & \\
\hline$<1$ & 5 & 2.24 & (0.65 to 7.72$)$ & 12 & 0.86 & (0.38 to 1.96$)$ \\
\hline$\geqslant 1$ & 1 & 0.77 & (0.08 to 7.34$)$ & 10 & 0.76 & $(0.31$ to 1.90$)$ \\
\hline Evaluation of trend $+\uparrow$ & & 1.29 & (0.61 to 2.73$)$ & & 0.87 & (0.60 to 1.25$)$ \\
\hline Likelihood ratio testł‡ & $\mathrm{p}=0.018$ & & & $\mathrm{p}=0$ & & \\
\hline
\end{tabular}

${ }^{\star} \mathrm{p}<0.05 ;{ }^{\star \star} \mathrm{p}<0.01 ;{ }^{\star \star \star} \mathrm{p}<0.001$.

†First diagnosis of chrome nasal ulcer.

$\ddagger$ Sore nose or chrome nasal ulcer.

§See footnote $\ddagger$, table 1 .

ISee footnote $\mathbb{\S}$, table 1 .

++ See footnote $+\dagger$, table 3

$\ddagger \ddagger$ See footnote $\neq \neq$, table 3 .

evaluated. Significant positive trends are shown for risk of lung cancer relative to duration of chrome bath work. (The significance of these trends was reduced marginally when employment histories were lagged by 10 years (not shown in table 3).) Duration of other chrome work was not a useful predictor of risk of lung cancer. Findings for all other causes of death were unexceptional.

The analyses shown in table 3 were repeated with additional statistical adjustment for other variables (calendar period, period from first chrome work, still employed or left employment, year of starting chrome work). Table 4 shows the findings for the duration of chrome work variables from the fuller models. Point estimates of risk for all durations of chrome bath work were increased.

Table 5 provides relative risks both for a diagnosis of chrome nasal ulceration and for a diagnosis of nasal problems (nasal ulcer or sore nose) by categories of cumulative duration of chrome work (chrome bath work and other chrome work analysed simultaneously). Details of these diagnoses were obtained from a review of factory medical records relating to the occupational health surveillance which was carried out on a fortnightly basis. (Also, the data relating to chrome nasal ulcers was double checked and supplemented with information maintained by the Health and Safety Executive.) Workers were not followed up for such diagnoses after leaving employment with the company. Consequently, for these analyses workers left the person-years at risk on date of first relevant diagnosis or date of leaving employment, whichever was earlier. Highly significant trends $(p<0.001)$ were found both for risk of chrome nasal ulceration and risk of nasal problems relative to cumulative duration of chrome bath work. Duration of other chrome work was unimportant.

\section{Discussion}

This investigation has provided further evidence that exposures associated with nickel/ chromium plating can lead to excess risks of lung cancer. Significant positive trends were shown for risks of lung cancer and duration of chrome bath work and these trends could not be explained by the potential confounding variables of sex, age, year of starting chrome work, period from first chrome work, and employment status. Nickel plating had also been carried out in many of the chrome plating workshops. It seems unlikely, however, that exposure to nickel (in the form of a mist of nickel sulphate and nickel chloride) is the cause of the excess risks because findings for lung cancer in a cohort of nickel platers (without any exposure to chrome plating) from the same factory were unexceptional. ${ }^{17}$ Nickel exposures would also have been much lower than chrome exposures because of the chemical and physical characteristics of the two types of baths. Other occupational exposures would have been present in the workshops and these would have included exposure to sulphuric acid, but given the strength of evidence for the carcinogenic potential of hexavalent chromium, ${ }^{2}$ exposure to chromic acid mist seems a likely causative factor.

The absence of an increased SMR for lung cancer in those who started chrome work in the period 1946-50 was unexpected. Too much should not be made of retrospective interpretation of small subgroup analyses, but the finding may represent more than a chance finding. It is often assumed that working conditions, in terms of occupational exposures, will always be worst in the earliest period under consideration. But this may be a naive assumption. The manual plating baths in operation in the 1940 s were replaced with semi-automatic baths in the early 1950s. Worker exposure to chromic acid mists may have been worse in the $1950 \mathrm{~s}$ than the $1940 \mathrm{~s}$ because a larger throughput of work was being carried out and the new baths may have been operated at higher electric current densities. ${ }^{18}$ The pattern of diagnosis of chrome ulceration is consistent with such a proposition. Of the 602 study subjects who started chrome work during the period 1946-50, four workers were diagnosed 
with chrome ulcers whereas of the 460 study subjects who started chrome work during the period 1951-55, 10 workers were diagnosed with chrome ulcers. The chrome ulceration problems at the plant were not eliminated until the 1970 s with the successful use of mist suppressants and local exhaust ventilation.

It was important to gain some independent evidence of whether cumulative duration of chrome bath work provided useful estimates of true exposure. Some supporting evidence is provided by the positive trends shown both for the risk of chrome nasal ulceration and the risk of nasal problems relative to cumulative duration of chrome bath work. Because of small numbers it was not possible to assess whether those diagnosed with chrome nasal ulcers or other nasal problems were at any special risk of lung cancer compared with other employees with similar exposures.

These data have limitations. Data on smoking histories were not available. Although the smoking habits of the cohort may well be different from those of the general population, it is not obvious why age specific smoking habits would be correlated with duration of chrome bath work, and it is just such a relation which would be required for smoking to be a confounding variable in the Poisson regression analyses. Unfortunately, the absence of data on smoking means that any interaction between chrome exposure and smoking habit cannot be investigated. Quantitative data or reliable estimates for the intensity of exposure to chromic acid mist by job and calendar period are currently not available. Also, original personnel records could not be found for all of the original cohort.

It is known from data collected by the company on a fortnightly basis that, for the period 1973 onwards, working exposure levels of chromic acid were almost always below 0.05 $\mathrm{mg} / \mathrm{m}^{3}$ (about $0.025 \mathrm{mg} / \mathrm{m}^{3}$ of chromium[VI]). Conditions in the earlier periods were almost certainly much worse. Even so, the current epidemiological findings suggest that a working lifetime at the United Kingdom maximum exposure limit (MEL) for hexavalent chromium of $0.05 \mathrm{mg} / \mathrm{m}^{3}$ time weighted average may present unacceptable risks.

1 Her Majesty's Factory Inspectorate, Department of Employment. Methods for the detection of toxic substances in air. Booklet No 17. Chromic acid mist. London: HMSO, 1967.

2 International Agency for Research on Cancer. IARC Monographs on the evaluation of carcinogenic risks to humans. Vol 49. Chromium, nickel and welding. Lyon: IARC, 1990.

3 Waterhouse JAH. Cancer among chromium platers [abstract]. Br F Cancer 1975;32:262.

4 Royle H. Toxicity of chromic acid in the chromium plating industry (1). Environ Res 1975;10:39-53.

5 Royle $\mathrm{H}$. Toxicity of chromic acid in the chromium plating Royle H. Toxicity of chromic acid in the ch.
industry (2). Environ Res 1975;10:141-63.

6 Okubo T, Tsuchiya K. An epidemiological study on lung Okubo T, Tsuchiya K. An epidemiological study on lung
cancer among chromium plating workers. Keio $f$ Med cancer among

7 Okubo T, Tsuchiya K. Epidemiological study of chromium platers in Japan. Biol Trace Elem Res 1979;1:35-44.

8 Silverstein M, Mirer F, Kotelchuck D, et al. Mortality among workers in a die-casting and electroplating plant. Scand f Work Environ Health 1981;7(suppl 4):156-65.

9 Franchini I, Magnani F, Mutti A. Mortality experience among chromeplating workers. Scand $f$ Work Environ Health 1983;9:247-52.

10 Sorahan T, Burges DCL, Waterhouse JAH. A mortality study of nickel/chromium platers. Br F Ind Med 1987;44: $250-8$.

11 Horiguchi S, Morinaga K, Endo G. Epidemiological study of mortality from cancer among chromium platers. Asia Pac f Public Health 1990;4:169-74.

12 Takahashi K, Okubo T. A prospective cohort study of chromium plating workers in Japan. Arch Environ Health 1990; 45:107-11.

13 Burges DCL. Manufacturing processes: electroplating. F Soc Occup Med 1977;27:114-7.

14 Epicure. Seattle, USA: Hirosoft International Corporation, 1988 .

15 Sorahan T, Cooke MA. Cancer mortality in a cohort of United Kingdom steel foundry workers: 1946-85. Br F Ind Med 1989;46:74-81

16 Breslow NE, Day NE. Statistical methods in cancer research. Vol II - The design and analysis of cohort studies. Lyon: International Agency for Research on Cancer, 1987. (IARC Sci Publ No 82.)

17 Pang D, Burges DCL, Sorahan T. Mortality study of nickel platers with special reference to cancers of the stomach and lung, 1945-93. Occup Environ Med 1996;53:714-7.

18 Guillemin MP, Berode M. A study of the difference in chromium exposure in workers in two types of electroplating process. Ann Occup Hyg 1978;21:105-12. 